Volume 4 Nomor 2, Agustus 2019, halaman 148 - 161

\title{
PENERAPAN PEMBELAJARAN REALISTIC MATHEMATIC EDUCATION BERBASIS ETNOMATEMATIKA UNTUK MENINGKATKAN HOTS MATEMATIK SISWA
}

\author{
ETHNOMATHEMATIC-BASED REALISTIC MATHEMATICS \\ LEARNING TO IMPROVE STUDENTS' MATHEMATICAL HOTS
}

\author{
Anisa Ardianingsih ${ }^{1}$, Desy Lusiyana ${ }^{2}$, Jajang Rahmatudin ${ }^{3}$ \\ ${ }^{1}$ Universitas Muhammadiyah Cirebon, Watubelah Cirebon, Ardianingsihzerozero@gmail.com \\ ${ }^{2}$ Universitas Muhammadiyah Cirebon, Watubelah Cirebon, Desylusiyana@gmail.com \\ ${ }^{3}$ Universitas Muhammadiyah Cirebon, Watubelah Cirebon, J.Rahmatudin87@gmail.com
}

\begin{abstract}
ABSTRAK
Kemampuan berpikir tingkat tinggi dibutuhkan untuk menghadapi tantangan revolusi industri 4.0 sedangkan kemampuan berpikir tingkat tinggi siswa SMP masih kategori rendah. Mengatasi hal tersebut, peneliti menerapkan pembelajaran realistic mathematic education berbasis etnomatematika yang mengkaji matematika dengan cara mengaitkan permasalahan matematika ke dalam budaya yang ada di sekitar siswa. Metode yang digunakan pada penelitian ini adalah kuasi eksperimen dengan desain penelitian yaitu nonequivalent pretest-posttest control group design. Populasi dalam penelitian ini adalah siswa kelas VII SMP Asy-Syahida Dukupuntang Kabupaten Cirebon tahun ajaran 2019/2020. Teknik pengambilan sampel yang digunakan adalah purposive sampling dengan sampel 31 siswa VII B sebagai kelas eksperimen dan 31 siswa VII A sebagai kelas kontrol. Teknik pengumpulan data pada penelitian ini menggunakan instrumen tes dengan 4 butir soal dan teknik analisis data menggunakan uji t dan Mann Withney $U$ dengan taraf signifikansi 5\%. Berdasarkan hasil analisis data dan pengujian hipotesis bahwa peningkatan HOTS matematik siswa yang menggunakan pembelajaran RME berbasis etnomatematika lebih baik dibandingkan dengan siswa yang menggunakan pembelajaran konvensional.
\end{abstract}

Kata kunci: High Order Thinking Skill, Realistic Mathematic Education, Etnomatematika

\begin{abstract}
High order thinking skills are needed to face the challenges of the industrial revolution 4.0 while the high order thinking skills of junior high school students are still in the low category. Overcoming this, the researcher applies ethnomatemics based realistic mathematic education that examines mathematics by linking mathematical problems to the culture around students. The method used in this study is a quasi-experimental research design that is nonequivalent pretestposttest control group design. The population in this study was grade VII ${ }^{\text {th }}$ students of Asy-Syahida Dukupuntang Junior High School, Cirebon Regency in the academic year 2019/2020. The sampling technique used was purposive sampling with the sample of 31 VII B students as the experimental class and 31 VII A students as the control class. Data collection techniques in this study used a test instrument with 4 items and data analysis techniques used the t test and Mann Withney $U$ with a significance level of 5\%. Based on the results of data analysis and hypothesis testing that the increase in mathematical HOTS of students using ethnomatemics based RME learning is better than students using conventional learning.
\end{abstract}

Keywords: High Order Thinking Skill, Realistic Mathematic Education, Ethnomathematic 


\section{How to Cite: Ardianingsih, A., Lusiyana, D., \& Rahmatudin, J. (2019). Penerapan Pembelajaran Realistic Mathematic Education Berbasis Etnomatematika untuk Meningkatkan HOTS Matematik Siswa. Mathline: Jurnal Matematika dan Pendidikan Matematika, Vol.4, No.2, 115-130.}

DOI :

\section{PENDAHULUAN}

Memasuki era revolusi industri 4.0, persaingan dan tantangan pendidikan semakin meningkat, sehingga permasalahan pendidikan di masa depan akan semakin kompleks dan harus segera direspon dengan cepat oleh pemerintah, pendidik dan tenaga kependidikan, serta stakeholder (Sani, 2019). Menghadapi tantangan perkembangan zaman, pelajar sebagai penerus bangsa diharapkan dapat memliki keterampilan berpikir tingkat tinggi untuk mengatasi permasalahan di masa depan. Dilihat dari hasil tes dan evaluasi survey PISA, Indonesia masih berada pada tingkat yang rendah pada performa sains, membaca dan matematika. Pada tahun 2012, hasil tes dan evalusai PISA menunjukkan bahwa Indonesia berada pada peringkat terakhir dan tahun 2015 Indonesia mengalami peningkatan yaitu berada pada peringkat di atas 60 dari 69 negara yang mengikuti tes survey tersebut. Walaupun Indonesia mengalami peningkatan peringkat dari tahun 2012 sampai tahun 2015, tetapi peningkatan tersebut tidak signifikan. Maka dari hasil tes evaluasi tersebut jika dibandingkan dengan negara-negara lain yang mengikuti tes, Indonesia masih terpaut jauh dengan negara lain dan salah satunya dalam kemampuan HOTS.

Berdasarkan hal tersebut, kemampuan berpikir tingkat tinggi atau high order thinking skill (HOTS) harus diterapkan dalam pembelajaran di sekolah. Salah satu solusi untuk meningkatkan HOTS matematik siswa dengan menggunakan pembelajaran yang berkaitan dengan permasalahan sehari-hari dan kebudayaan yang akrab dengan siswa agar matematika lebih mudah diterima oleh siswa. Pembelajaran yang menyajikan permasalahan matematika ke dalam permasalahan dunia nyata salah satunya yaitu pembelajaran Realistic Mathematic Education berbasis etnomatematika.

Etnomatematika merupakan unsur matematika yang diterapkan oleh kelompok budaya tertentu dalam kehidupan dan aktivitas mereka. (Dwidayati \& Zaenuri, 2018). Pembelajaran berbasis etnomatematika artinya mengaitkan permasalahan matematika dengan kebudayaan yang ada pada daerah tersebut atau akrab dengan siswa. Dalam hal ini, 
penelitian ini menggunakan batu alam berpola alur matahari dari hasil kebudayaan Dukupuntang-Cirebon sebagai sarana etnomatematika. Sejalan dengan pembelajaran berbasis etnomatematika, pembelajaran Realistic Matematics Education menekankan pada realita serta aktivitas sehari-hari manusia. Maka siswa akan mampu mengkontruksikan pengetahuan mereka yang diperoleh melalui pengalaman langsung (Puri, dkk, 2017).

Etnomatematika diperkenalkan pertama kali pada tahun 1977 oleh D’Ambrosio yaitu seorang matematikawan yang berasal dari Brazil. Etnomatematika berasal dari kata "ethnomathematics" yaitu "ethno" diartikan sebagai sesuatu yang luas serta mengacu pada konteks sosial budaya yang di dalamnya termasuk bahasa, jargon, kode-kode perilaku, mitos maupun simbol yang ada pada suatu kelompok budaya. Kata kedua yaitu kata "mathema" yang artinya lebih cenderung kepada menjelaskan, mengetahui, memahami, serta melakukan kegiatan-kegiatan yang berhubungan dengan matematika seperti pengkodean, mengukur, mengukur, mengklarifikasi, menyimpulkan, serta pemodelan. Sedangkan kata terakhir yaitu "tics" berasal dari kata techne dan bermakna sama seperti teknik (Hardiarti, 2017).

Penggunaan etnomatematika pada penelitian ini yaitu dengan batu alam. Batu alam atau lebih dikenal sebagai batu-batuan merupakan benda keras yang banyak ditemui serta banyak digunakan sebagai bahan material bangunan atau sebagai dekorasi interior maupun eksterior. Batu alam banyak juga banyak didataran tinggi atau perbukitan. Jenis batu alam yang sering digunakan sebagai bahan material bangunan ataupun dekorasi interior maupun eksterior adalah jenis batu marmer, batu paras (lime stone), batu mulia dan batu kali (Hananto, 2006).

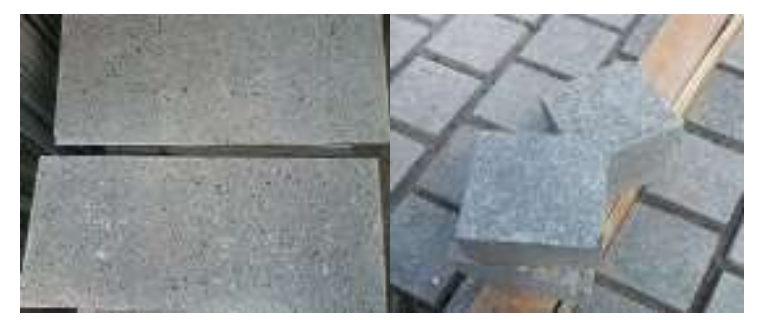

\section{Gambar 1. Contoh Bentuk Batu Alam}

Bentuk dari batu alam yang biasa ditemui adalah bentuk bangun datar persegi panjang dan persegi. Berdasarkan hal tersebut, batu alam merupakan objek yang cocok untuk pembelajaran materi segiempat dan segitiga di tingkat kelas VII SMP. Pembelajaran menggunakan benda konkret seperti batu alam dapat memudahkan siswa untuk memahami materi secara lebih realistik. Maka dapat disimpulkan bahwa pembelajaran etnomatematika sejalan dengan pembelajaran Realistic Mathematic Education. 
RME adalah teori belajar mengajar dalam matematika diperkenalkan dan dikembangkan pertama kali oleh Institut Freudhental pada tahun 1970. Teori RME mengacu pada pendapat Freundhental yaitu matematika harus selalu dikaitkan dengan realita ataupun kenyataan karena segala aktifitas manusia merupakan kegiatan matematika (Darmawanti, dkk, 2016). Artinya pembelajaran RME mengkaji matematika menjadi suatu hal yang relevan dengan siswa.

Pandangan penting Freundenthal di dalam pembelajaran matematika yaitu "mathematics must be connected to reality and mathematics as human activity" yang artinya matematika harus berkaitan dengan kenyataan dan matematika adalah sebagai aktifitas manusia (Zakaria \& Syamaun, 2017). Pembelajaran matematika harus selalu dikaitkan dengan kehidupan sehari-hari agar pemahaman konsep matematika secara abstrak dapat dipahami oleh siswa. Aktifitas manusia hampir keseluruhan merupakan kegiatan yang dilakukan dengan konsep matematika yang tanpa disadari sangat dipahami oleh manusia, misalnya mengenai bentuk bangun datar, bilangan, penjumlahan dan kegiatan-kegiatan manusia yang lainnya.

Pembelajaran RME memiliki tahapan atau langkah-langkah secara umum yaitu sebagai berikut (Lestari, 2014):

a. Memahami permasalahan kontekstual

b. Menyelesaikan permasalahan

c. Membandingkan serta mendiskusikan jawaban

d. Menarik kesimpulan dari suatu permasalahan

Adapun pembelajaran RME berbasis etnomatematika memiliki langkah-langkah yaitu (Maulidiyah, 2018):

a. Tahap Awal

Guru membuka pelajaran kemudian memberikan motivasi kepada siswa dan menyampaikan tujuan pembelajaran materi segitiga dan segiempat sesuai dengan KI dan KD.

b. Tahap I (Memahami Masalah Kontekstual)

Guru menyajikan masalah kontekstual dengan menggunakan beberapa soal kontekstual dalam bentuk soal cerita yang mengaitkan media pembelajaran berupa batu alam yang telah dibagikan ke masing-masing kelompok untuk dianalisa

c. Tahap II (Menyelesaikan Masalah)

Setiap kelompok mengidentifikasi dan menganalisis permasalahan dengan mengamati batu alam, serta menyelesaikan masalah yang telah diberikan oleh guru.

d. Tahap III (Membandingkan dan Mendiskusikan Jwaban)

Guru mengarahkan siswa untuk mempersiapkan jawaban kelompok mereka untuk diskusi kelas.

e. Tahap IV (Menyimpulkan) 
Guru membimbing dan mengarahkan siswa dalam membuat kesimpulan yang tepat mengenai materi yang telah dipelajari

Berdasarkan sintak pembelajaran RME berbasis etnomatematika, dapat disimpulkan bahwa pembelajaran RME berbasis etnomatematika merupakan pembelajaran yang mengedepankan pengalaman langsung siswa terhadap matematika sehingga siswa dengan mudah mengaitkan matematika dengan kehiduapan nyata agar konsep-konsep matematika lebih mudah dipahami dan diingat oleh siswa. Pembelajaran yang menjadikan matematika permasalahan sehari-hari yang berkaitan erat dengan siswa, maka pembelajaran RME berbasis etnomatematika menjadi solusi pembelajaran yang bertujuan untuk meningkatkan kemampuan HOTS.

HOTS menurut Conklin yaitu "characteristics of higher order tniking skills encompass both critical thinking and creative thinking" yang memiliki arti "Karakteristik keterampilan berpikir tingkat tinggi mencakup pemikiran kritis dan pemikiran kreatif". High Order Thinking Skill memiliki dua karakteristik utama yaitu berpikir kritis serta kreatif (Conklin \& Manfro, 2012). Adapun HOTS menurut Lewis da Smith adalah " $a$ broader term than critical thinking is needed to include problem solving, critical thinking, creative thinking, and decision making” yang berarti "istilah yang lebih luas dari berpikir tingkat tinggi yaitu harus meliputi pemecahan masalah, berpikir kritis, berpikir kreatif, serta membuat keputusan". Maka karakteristik HOTS menurut Lewis dan Smith adalah 1) Pemecahan Masalah, 2) Berpikir Kritis, 3) Berpikir Kreatif, dan 4) Membuat Keputusan (Lewis \& Smith, 1993).

\section{Kemampuan Menyelesaikan Permasalahan (Problem Solving)}

Seseorang tidak pernah terlepas dengan masalah selama hidupnya dan juga seseorang dituntut untuk dapat menyelesaikan masalahnya dalam setiap aspek kehidupan mereka. Problem solving adalah suatu proses yang meliputi visualisasi, sosiasi, abstraksi, pemahaman, manipulasi, bernalar, analisis, sintesis, serta generalisasi dengan setiap aspek harus diatur dan dikoordinasikan (Sani, 2019).

Menurut Dewey (1933), ada lima kategori yang harus dimiliki dalam kemampuan pemecahan masalah. Adapun masing-masing dari kategori tersebut adalah 1) Konfrontasi Masalah, 2) Diagnosa atau mendefinisikan masalah, 3) Inventarisasi beberapa solusi, 4) Menduga konsekuensi solusi, 5) Menguji konsekuensi (Dewey, 1933). 


\section{Berpikir Kritis}

Berpikir kritis adalah suatu proses berpikir terampil serta tanggung jawab ketika seseorang mempelajari permasalahan dari setiap sudut pandang serta terlibat dalam penyelidikan sehingga memperoleh opini, penilaian ataupun pertimbangan yang terbaik dengan menggunakan kecerdasan dalam mengambil suatu kesimpulan (Sies, 1998). Cerdas dalam mengambil kesimpulan merupakan suatu kegiatan yang dituju dalam kemampuan berpikir kritis.

Kemampuan berpikir kritis meliputi kejelasan, ketelitian, relevansi, kedalaman, konsistensi, logika, kesesuaian serta signifikansi. Seorang yang berpikir kritis akan selalau berusaha untuk mencari alasan suatu pemikiran, informasi yang cukup, menggunakan sumber-sumber terpercayadan juga dapat menyatakan sumber tersebut, mencari alternatif, mempertimbangkan pandangan orang lain serta diri sendiri dengan serius, menahan pertimbangan jika bukti yang dimiliki belum kuat, dan juga selalu mencari informasi sebanyak mungkin dengan akurat. Seseorang yang dapat berpikir kritis maka akan dapat bertindak dengan mengambil keputasan melalui pertimbangan yang jelas dan rasional (Sani, 2019).

Adapun menurut Mc. Lean (2005), ada empat kategori utama yang harus dimiliki dalam kemampuan berpikir kritis. Masing-masing dari kategori tersebut yaitu 1) Klarifikasi tesis, permasalahan, dan interpretasi, 2) membuat inferensi dan interpretasi, 3)Mendukung inferensi dan interpretasi, dan 4) memutuskan membuat nilai

\section{Berpikir Kreatif}

Kreativitas dapat didefinisikan sebagai suatu proses untuk menghasilkan sesuatu yang baru dari elemen yang ada dengan cara menyusun kembali elemen tersebut ke dalam bentuk yang baru. Setiap individu memiliki kreativitas yang berbeda-beda sesuai dengan cara pendekatan terhadap masalah yang mereka gunakan (Downing, 1997) Adapun kriteria utama kreativitas menurut Torrance (1990) adalah sebagai berikut (Sani, 2019):
a. Kelancaran : menghasilkan banyak ide
b. Keaslian : menghasilkan ide-ide baru atau ide yang sebelumnya tidak ada
c. Fleksibelitas : kemampuan menghasilkan ide-ide yang bervariasi
d. Elaborasi : mengembangkan atau menambahkan ide-ide sehingga dihasilkan ide yang lebih detail


Berdasarkan latar belakang penelitian, maka permasalahan yang ada pada penelitian ini dirumuskan sebagai berikut :

1. Apakah terdapat perbedaan kemampuan HOTS matematika siswa antara siswa yang pembelajarannya menggunakan RME berbasis Etnomatematika dengan siswa yang pembelajarannya menggunakan PBL ?

2. Apakah terjadi perbedaan peningkatan kemampuan HOTS matematika siswa antara siswa yang pembelajaran menggunakan RME berbasis etnomatematika serta siswa yang pembelajarannya menggunakan PBL ?

Penelitian ini memiliki 2 tujuan untuk menjawab rumusan masalah yang ditetapkan. Berikut merupakan tujuan dari penelitian ini :

1. Mengetahui adanya perbedaan kemampuan HOTS matematik siswa antara siswa yang pembelajarannya menggunakan RME berbasis Etnomatematika dengan siswa yang pembelajarannya menggunakan PBL.

2. Mengetahui adanya perbedaan peningkatan kemampuan HOTS matematik siswa antara siswa yang pembelajaran menggunakan RME berbasis etnomatematika serta siswa yang pembelajarannya menggunakan PBL.

\section{METODE PENELITIAN}

Metode penelitian ini menggunakan metode kuantitatif. Penerapan penelitian ini menggunakan metode kuasi eksperimen yaitu menguji coba langsung terhadap sampel yang ditentukan pada penelitian, sedangkan untuk desain penelitian ini yaitu menggunakan non-equivalent control group design. Adapun paradigma desain dari Nonequivalent Control Group Design dapat digambarkan sebagai berikut (Sugiyono, 2018):

\begin{tabular}{|lll|}
\hline $\mathbf{O}_{1}$ & $\mathbf{X}$ & $\mathbf{O}_{2}$ \\
\hline $\mathbf{O}_{3}$ & & $\mathbf{O}_{4}$ \\
\hline
\end{tabular}

Keterangan :

\section{Gambar 2. Nonequivalent Control Group Design}

$\mathrm{X}_{1} \quad=$ Treatment menggunakan RME berbasis etnomatematika

$\mathrm{O}_{1}, \mathrm{O}_{3}=$ Pre-Test

$\mathrm{O}_{2}, \mathrm{O}_{4}=$ Post-Test

Penelitian ini dilakukan dengan cara menentukan dua buah kelas. Salah satu kelas dijadikan kelas eksperimen untuk pengujian penelitian dan diberikan penerapan atau 
perlakuan, sedangkan satu kelas yang lainnya menjadi kelas kontrol yang tidak diberikan perlakuan yang baru melainkan perlakuan yang sama sebelum adanya penelitian.

Peneltian ini menggunakan instrumen untuk mengukur kemampuan dan peningkatan HOTS yaitu instrumen tes berupa pre-test dan post-test dengan jumlah butir soal sebanyak 4 buah yang mewakili indikator dari HOTS pada aspek kemampuan berpikir kritis, kreatif, pemecahan masalah, dan membuat keputusan dengan bentuk soal yang selalu mengaitkan etnomatematika batu alam. Subjek penelitian ini adalah siswa kelas VII SMP Asy-Syahida Dukupuntang Kabupaten Cirebon tahun ajaran 2019/2020 dengan sampel yaitu 31 siswa kelas VII B sebagai kelas eksperimen dan 31 siswa kelas VII A sebagai kelas kontrol dengan teknik pengambilan sampel menggunakan purposive sampling.

Sebelum menerapkan perlakuan pada kelas eksperimen dan kontrol, peneliti melakukan pre-test terlebih dahulu. Pre-test dilakukan pada kelas eksperimen dan kelas kontrol untuk mengetahui kemampuan awal siswa terhadap kemampuan HOTS matematik. Langkah selanjutnya yaitu penerapan perlakuan terhadap kelas ekperimen dan kelas kontrol. Pada kelas eksperimen, pembelajaran menggunakan pembelajaran RME berbasis etnomatematika sedangkan pada kelas kontrol menggunakan pembelajaran secara konvensional yaitu PBL. Adapun langkah ketiga dalam penelitian yaitu melakukan posttest. Post-test dilakukan ketika indikator pencapaian dalam pembelajaran sudah terpenuhi. Post-test dilakukan untuk mengetahui perbedaan dan peningkatan kemampuan HOTS matematik siswa setelah diterapkannya perlakuan yang berbeda pada kelas eksperimen dan kelas kontrol.

Analsis data penelitian ini menggunakan Uji T dengan taraf signifikansi 5\% untuk mengetahui hasil akhir dari pengujian hipotesis yang telah ditetapkan. Peneliti melakukan uji normalitas dan uji homogenitas sebagai prasyarat untuk melakukan uji hipotesis menggunakan statistik parametrik. Uji analisis data pada penelitian ini dilakukan dengan bantuan SPSS for Windows Versi 25.

\section{HASIL DAN PEMBAHASAN}

Dari hasil deskriptif data pre-test kelas eksperimen dan kontrol memiliki nilai yang tidak terpaut jauh, berbeda dengan hasil deskrtiptif data post-test yang memiliki perbedaan cukup signifikan. Adapun hasil secara umum dari pre-test dan post-test sebagai berikut: 
Tabel 1. Hasil Deskripsi Pre-Test dan Post-Test

\begin{tabular}{ccccccc}
\hline \multirow{2}{*}{ Data } & Kelas & N & Mean & $\begin{array}{c}\text { Std. } \\
\text { Deviation }\end{array}$ & Min & Max \\
\hline \multirow{2}{*}{ Pre-test } & Eksperimen & 31 & 5,77 & 1,499 & 3 & 9 \\
\cline { 2 - 7 } & Kontrol & 31 & 5,19 & 1,778 & 0 & 9 \\
\hline \multirow{2}{*}{ Post-test } & Eksperimen & 31 & 9,94 & 2,220 & 4 & 14 \\
\cline { 2 - 7 } & Kontrol & 31 & 8,35 & 1,889 & 4 & 13 \\
\hline
\end{tabular}

Berikut adalah diagram yang menggambarkan secara umum hasil deskriptif data pretest dan post-test.

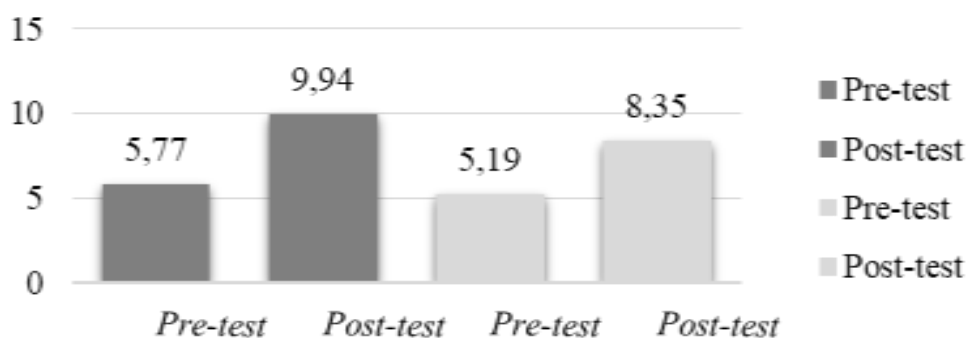

Gambar 3. Deskriptif Data Pre-test dan Post-test

Berdasarkan tabel dan diagram di atas, dapat dilihat bahwa kemampuan awal HOTS siswa antar kelas eksperimen dan kontrol awal mulanya tidak jauh berbeda yaitu selisih 0,58, sedangkan pada kemampuan akhir HOTS siswa kelas eksperimen dan kontrol memiliki selisih 1,59. Maka pada kemampuan akhir HOTS siswa terdapat perbedaan yang signifikan walaupun kemampuan awal HOTS siswa tidak jauh berbeda. Pada penelitian ini terdapat dua permasalahan yang diteliti yaitu kemampuan HOTS matematik siswa dan peningkatan kemampuan HOTS matematik siswa. Adapun mengenai hasil secara lebih rinci yaitu sebagai berikut:

\section{Kemampuan HOTS Matematik Siswa}

Penelitian dilakukan dengan menerapkan dua perlakuan yang berbeda di dua kelas. Kelas eksperimen menggunakan pembelajaran RME berbasis etnomatematika, sedangkan kelas kontrol menggunakan pembelajaran konvensional. Dari hasil pre-test dan juga post-test akan diuji normalitas dan homogenitas sebagai uji prasyarat untuk melakukan uji hipotesis atau uji rerata persamaan pre-test dan uji rerata perbedaan post-test. 
Pengujian hipotesis dilakukan setelah uji prasyarat telah memenuhi. Berikut merupakan hasil dari uji normalitas data pre-test dan post-test:

Tabel 2. Data Hasil Uji Normalitas Nilai Pre-test dan Post-test Kemampuan HOTS Matematik

\begin{tabular}{cllccl}
\hline \multirow{2}{*}{ Nilai } & \multirow{2}{*}{ Kelompok } & \multicolumn{3}{c}{ Shapiro-Wilk } & \multirow{2}{*}{ Kesimpulan } \\
\cline { 3 - 5 } & Statistic & $d f$ & Sig. & \\
\hline \multirow{2}{*}{ pre_test } & Eksperimen & 0,943 & 31 & 0,101 & Berdistribusi normal \\
\cline { 2 - 5 } & Kontrol & 0,940 & 31 & 0,083 & Berdistribusi normal \\
\hline \multirow{2}{*}{ post_test } & Eksperimen & 0,942 & 31 & 0,095 & Berdistribusi normal \\
\cline { 2 - 5 } & Kontrol & 0,957 & 31 & 0,240 & Berdistribusi normal
\end{tabular}

Setelah dilakukan uji normalitas, diperoleh data pre-test dan post-test yang seluruhnya berdistribusi normal sehingga tahap selanjutnya dilakukan uji homogenitas. Uji homogenitas dilakukan melalui uji $F$ atau Levene's test menggunakan taraf signifikansi $\alpha=0,05$, maka kriteria pengambilan keputusannya yaitu jika nilai signifikansinya $\geq 0,05$ maka $H_{0}$ diterima, sedangkan jika nilai signifikansinya $<0,05$ maka $H_{0}$ ditolak. Berikut hasil uji homogenitas Levene's Statistic data pre-test dan post-test:

Tabel 3. Data Hasil Uji Homogenitas Data Pre-test dan Post-test Kemampuan HOTS Matematik

\begin{tabular}{|c|c|c|c|}
\hline \multirow{2}{*}{ Data } & \multicolumn{2}{|c|}{ Levene Statistic } & \multirow{2}{*}{ Keterangan } \\
\hline & $\boldsymbol{F}$ & Sig. & \\
\hline Pre_test & 1,932 & 0,170 & Bervariansi homogen \\
\hline Post_test & 9,113 & 0,004 & $\begin{array}{c}\text { Tidak bervariansi } \\
\text { homogen }\end{array}$ \\
\hline
\end{tabular}

Pada penelitain ini, pengujian prasyarat terpenuhi seluruhnya sehingga pengujian hipotesis menggunakan statistika parametrik Uji T-Test dengan signifikansi 0,05. Berikut merupakan hasil dari analisis data :

\begin{tabular}{cccc}
\multicolumn{2}{c}{ Tabel 4. Hasil Uji Rerata Persamaan Pre-Test } \\
\hline \multirow{2}{*}{ Data } & \multicolumn{2}{c}{ Independent Samples Test } & \multirow{2}{*}{ Keterangan } \\
\cline { 2 - 3 } & $\mathbf{T}$ & Sig.(2-tailed) & \\
\hline Pre-test & 0,201 & 0,655 & $H_{0}$ diterima \\
\hline
\end{tabular}

Tabel di atas merupakan hasil dari uji rerata persamaan Pre-test yang bertujuan untuk mengetahui apakah ada persamaan kemampuan HOTS matematik antara kelas 
eksperimen dengan kelas kontrol. Berdasarkan tabel di atas, dapat dilihat bahwa nilai sig. 0,655 $\geq 0,05$ sehingga $H_{0}$ diterima. Kemudian, akan dilakukan analisis uji rerata perbedaan Post-test dengan hasil sebagai berikut:

Tabel 5. Hasil Uji Rerata Perbedaan Post-Test

\begin{tabular}{cccc}
\hline \multirow{2}{*}{ Data } & \multicolumn{2}{c}{ Independent Samples Test } & \multirow{2}{*}{ Keterangan } \\
\cline { 2 - 3 } & T (not assumed) & Sig.(2-tailed) & \\
\hline Post-test & 3,019 & 0,004 & $H_{0}$ ditolak \\
\hline
\end{tabular}

Berdasarkan tabel di atas, pengujian data rerata perbedaan post-test menghasilkan nilai sig. 0,004 $<0,05$ sehingga $H_{0}$ ditolak. Maka dapat disimpulkan bahwa terdapat perbedaan kemampuan HOTS matematik antara siswa di kelas eksperimen yang menggunakan pembelajaran RME berbasis etnomatematika dengan siswa di kelas kontrol yang menggunakan pembelajaran konvensional.

Dilihat dari hasil uji persamaan pre-test dan uji perbedaan post-test menunjukkan bahwa kemampuan HOTS matematik siswa pada mulanya setara atau tidak terdapat perbedaan yang signifikan, tetapi setelah memperoleh perlakuan kemampuan HOTS matematik siswa terdapat perbedaan yang signifikan. Maka dapat disimpulkan bahwa terdapat perbedaan kemampuan HOTS matematik siswa yang menggunakan pembelajaran RME berbasis etnomatematika dengan siswa yang menggunakan pembelajaran konvensional.

\section{Peningkatan Kemampuan HOTS Matematik Siswa}

Peningkatan kemampuan HOTS matematik siswa dapat dilihat melalui Analisis skor $N$-Gain. Uji hipotesis $N$-Gain dilakukan setelah uji prasayat telah terpenuhi yaitu uji normalitas dan uji homogenitas. Uji normalitas skor $N$-Gain test pada penelitian ini mengunakan uji Shapiro-Wilk karena jumlah siswa kedua kelas yaitu lebih dari 30 siswa. Uji Shapiro-Wilk dilakukan dengan bantuan Software SPSS Versi 25 for Windows. Taraf signifikansi yang digunakan dalam uji normalitas $N$-Gain Test yaitu $\alpha=0,05$. Berdasarkan taraf signifikansi yang digunakan maka kriteria pengambilan keputusannya yaitu jika nilai signifikansi $\geq 0,05$ maka $H_{0}$ diterima, sedangkan jika nilai signifikansi $<0,05$ maka $H_{0}$ ditolak. Berikut hasil uji normalitas Shapiro-Wilk data $N$-Gain secara umum : 
Tabel 6. Data Hasil Uji Normalitas Nilai $N$-Gain Kemampuan HOTS Matematik

\begin{tabular}{clcccc}
\hline \multirow{2}{*}{ Nilai } & \multirow{2}{*}{ Kelas } & \multicolumn{3}{c}{ Shapiro-Wilk } & \multirow{2}{*}{ Keterangan } \\
\cline { 3 - 5 } & & Statistic & $\boldsymbol{d} \boldsymbol{f}$ & Sig. & \\
\hline \multirow{2}{*}{$N_{\text {gain }}$} & Eksperimen & 0,963 & 32 & 0,350 & Berdistribusi normal \\
\cline { 2 - 5 } & Kontrol & 0,949 & 32 & 0,144 & Berdistribusi normal \\
\hline
\end{tabular}

Setelah dilakukan uji normalitas, diperoleh data $N$-Gain yang berdistribusi normal sehingga tahap selanjutnya dilakukan uji homogenitas. Uji homogenitas dilakukan melalui uji $F$ atau Levene's test menggunakan taraf signifikansi $\alpha=0,05$, maka kriteria pengambilan keputusannya yaitu jika nilai signifikansinya $\geq 0,05$ maka $H_{0}$ diterima, sedangkan jika nilai signifikansinya $<0,05$ maka $H_{0}$ ditolak. Berikut hasil uji homogenitas Levene's Statistic data N-Gain:

Tabel 7. Data Hasil Uji Homogenitas Data N-Gain Kemampuan HOTS Matematik

\begin{tabular}{cccc}
\hline \multirow{2}{*}{ Data } & \multicolumn{2}{c}{ Levene Statistic } & Keterangan \\
\cline { 2 - 3 }$N$-Gain & $\boldsymbol{F}$ & Sig. & \\
\hline & 15,292 &, 000 & $\begin{array}{c}\text { Tidak bervariansi } \\
\text { homogen }\end{array}$ \\
\hline
\end{tabular}

Pada penelitian ini, uji prasyarat sudah terpenuhi seluruhnya maka akan dilakukan uji rerata perbedaan skor $\mathrm{N}$-Gain menggunakan statistik parametrik untuk dilakukan uji hipotesis. Berikut merupakan hasil analsisnya :

Tabel 8. Hasil Uji Rerata Perbedaan $N$-Gain

\begin{tabular}{cccc}
\hline \multirow{2}{*}{ Data } & \multicolumn{2}{c}{ Independent Samples Test } & \multirow{2}{*}{ Keterangan } \\
\cline { 2 - 3 } & T (not assumed) & Sig.(2-tailed) & \\
\hline Post-test & 3,019 & 0,004 & $H_{0}$ ditolak \\
\hline
\end{tabular}

Berdasarkan tabel di atas, hasil dari analsis uji rerata perbedaan $\mathrm{N}$-Gain memperoleh nilai sig. 0,004 $<0,05$ sehingga $H_{0}$ ditolak. Maka dari hasil analsis tersebut terdapat peningkatan kemampuan HOTS matematik siswa yang menggunakan pembelajaran RME berbasis etnomatematika dibandingkan siswa yang menggunakan pembelajarna konvensional.

Dilihat dari uji analsis data yang telah dilakukan maka dapat dikatakan bahwa kemampuan HOTS matematik siswa lebih tinggi dengan menggunakan pembelajaran RME 
berbasis etnomatematika jika dibandingkan dengan menggunakan pembelajaran yang konvensional. Dari hasil analisis tersebut juga dapat disimpulkan bahawa penerapan pembelajaran RME berbasis etnomatematika dapat meningkatkan kemampuan HOTS matematik siswa lebih baik dibandingkan dengan pembelajaran konvensional.

\section{KESIMPULAN}

Pre-test dan post-test dilakukan pada dua kelas yang menjadi kelas eksperimen dan kelas kontrol pada penelitian. Berdasarkan hasil penelitian kuantitatif yang dilakukan dengan teknik penelitian desain eksperimen di SMP Asy-Syahida Dukupuntang Kabupaten Cirebon tentang pembelajaran RME berbasis etnomatematika dalam meningkatkan kemampuan HOTS matematik siswa menghasilkan beberapa kesimpulan yang dapat menjawab rumusan masalah penelitian. Kesimpulan yang dapat dipaparkan oleh peneliti yaitu sebagai berikut :

1. Kemampuan HOTS matematik siswa dengan menggunakan pembelajaran RME berbasis etnomatematika lebih baik dibandingkan siswa yang menggunakan pembelajaran konvensional. Hal tersebut dapat dilihat dari hasil analisis uji Independent Sample T-Test yaitu nilai sig. (1-tailed) 0,000<0,05 sehingga $H_{0}$ ditolak.

2. Peningkatan kemampuan HOTS matematik siswa dengan menggunakan pembelajaran RME berbasis etnomatematika lebih baik dibandingkan siswa yang menggunakan pembelajaran konvensional. Hal tersebut dapat dilihat dari hasil analisis uji perbedaan rerata $\mathrm{N}$-Gain menggunakan statistika non parametrik yaitu uji Mann-Withney $U$ dengan hasil sig.(1-tailed) yang diperoleh yaitu $0,000<0,05$ sehingga $\mathrm{H}_{0}$ ditolak

\section{Daftar Pustaka}

Conklin, W., \& Manfro, J. (2012). Higher Order Thinking Skills to Develop 21st Century Learners. Huntington: Shell Education Publishing. Dipetik Mei 11, 2019, dari https://genfanook.firebaseapp.com/aa908/higher-order-thinking-skills-to-develop21st-century-learners-by-wendy-conklin-1425808220.pdf

Darmawanti, S., Sutarto, \& Yuntawati. (2016). Penerapan Realistic Mathematics Education ( Rme ) Untuk Meningkatkan Minat Dan Hasil Belajar Matematika Siswa Kelas Viii Mts.Al-Ma'arif Nu Sinah Tahun Pelajaran 2016/2017. Dipetik April 10, 2019, dari http://ojs.ikipmataram.ac.id/index.php/jmpm/article/view/497

Dewey, J. (1933). How We Think. Boston: D. C. Heath.

Downing, J. (1997). Creative Teaching : Ideas to Boost Student Interest. Colorado: Libraries Unlimited. 
Dwidayati, N., \& Zaenuri. (2018). Menggali Etnomatematika: Matematika sebagai Produk Budaya. PRISMA. Dipetik Juni 12, 2019, dari https://journal.unnes.ac.id/sju/index.php/prisma/article/view/20136/9540

Hananto, A. D. (2006). Skripsi Mengenai Studi Tentang Kerajinan Batu Alam Pada CV. Chadas Roma, Sewon, Bantul, Yogyakarta. Dipetik Juni 13, 2019, dari file:///C:/Users/Win7/Downloads/Arif\%20Dwi\%20Hananto.pdf

Hardiarti, S. (2017). Aplikasi Bangun Datar Segiempat Pada Candi Muaro Jambi. Aksioma, 8. Dipetik Juni 14, 2019, dari https://media.neliti.com/media/publications/217393none.pdf

Jumaisyaroh, T., Napitupulu, E., \& Hasratuddin. (2015). Peningkatan Kemampuan Berpikir Kritis Matematis Dan Kemandirian Belajar Siswa Smp Melalui Pembelajaran Berbasis Masalah. Medan: Universitas Negeri Medan. Dipetik Juni 22, 2019, dari https://media.neliti.com/media/publications/56718-ID-peningkatankemampuan-berpikir-kritis-ma.pdf

Lestari, A. (2014). Penerapan Pendekatan Realistic Mathematics Education Untuk Meningkatkan Hasil Belajar Siswa Pada Materisoal Cerita Tentang Himpunan Di Kelas Vii Mtsn Palu Barat. Dipetik Juni 12, 2019, dari http://jurnal.untad.ac.id/jurnal/index.php/JEPMT/article/view/3226/2281

Lewis, A., \& Smith, D. (1993). Defining Higher Order Thinking.

Maulidiyah, A. (2018). Pengembangan Perangkat Pembelajaran Matematika Dengan Pendekatan Rme (Realistic Mathematic Education) Berbasis Ethnomatematika Dalam Seni Arabesque Pada Materi Geometri. Dipetik 2019, dari http://digilib.uinsby.ac.id/28702/7/Alimatul\%20Maulidiyah_D94214092.pdf

McLean, C. L. (2005). Evaluating Critical Thinking Skills: Two Conceptualizations. JOURNAL OF DISTANCE EDUCATION.

Puri, D. A., Lestari, L., \& Atmojo, I. R. (2017). Enerapan Pendekatan Realistic Mathematics Education (Rme) Untuk Meningkatkan Pemahaman Konsep SifatSifat Bangun Ruang Pada Siswa Sekolah Dasar. Dipetik Juni 11, 2019, dari file://C:/Users/Win7/Downloads/10458-22497-1-PB\%20(1).pdf

Sani, R. A. (2019). Pembelajaran Berbasis HOTS Edisi Revisi. Tangerang: Tira Smart.

Sies, M. (1998). Critical Thinking Talking Points.

Simon, H. (1977). Administrative Behavior (4th expanded edition; first edition 1947). New York: The Free Press.

Sternberg, R., \& O'Hara, L. (1998). Creativity and inteligence in Handbook of Creativity. Cambridge University Press.

Sugiyono. (2018). Metode Penelitian Pendidikan. Bandung: Alfabeta.

Zakaria, E., \& Syamaun, M. (2017). The Effect of Realistic Mathematics Education Approach on Students' Achievement And Attitudes Towards Mathematics. Mathematics Education Trends and Research. 